\title{
A COMPETÊNCIA EM INFORMAÇÃO E O COMPORTAMENTO INFORMACIONAL DOS USUÁRIOS DE BIBLIOTECAS HÍBRIDAS: UM ESTUDO COMPARATIVO NO BRASIL E NA ESCÓCIA
}

\author{
THE INFORMATION LITERACY AND THE \\ INFORMATION BEHAVIOUR OF HYBRID \\ LIBRARIES USERS: A COMPARATIVE STUDY \\ BETWEEN BRAZIL AND SCOTLAND
}

\author{
Rafaela Carolina Silvaa \\ Selma Letícia Capinzaiki Ottonicar ${ }^{\text {b }}$ \\ Rosângela Formentini Caldasc \\ Cláudio Marcondes de Castro Filho ${ }^{d}$
}

\begin{abstract}
RESUMO
Introdução: As bibliotecas híbridas possuem vários recursos a oferecer para os usuários. Assim, eles precisam ser competentes em informação para conseguir acessar, avaliar e usar a informação nessas bibliotecas. Além disso, eles precisam desenvolver seu comportamento informacional para acessar as informações de maneira efetiva. Objetivos: A pesquisa busca refletir sobre a relação da competência em informação e do comportamento informacional no contexto das bibliotecas híbridas. Metodologia: A Análise de Conteúdo foi usada para levantar os indicadores de bibliotecas híbridas a serem estudados. Utilizou-se o Estudo de Casos Múltiplos para comparar a relação da competência em informação e do comportamento informacional no contexto das bibliotecas híbridas do Brasil e do Reino Unido. Resultados: Com a bagagem teórica que a revisão de literatura trouxe, juntamente com os dados levantados no Estudo de Caso, construiu-se um quadro teórico interrelacionando as temáticas estudadas no âmbito da hibridez. Conclusões: destacou-se que as bibliotecas híbridas se utilizam da competência em informação e do

a Mestra em Ciência da Informação pela Universidade Estadual Paulista - UNESP (Câmpus Marília). E-mail: rafacarolina@marilia.unesp.br

b Doutoranda em Ciência da Informação pela Universidade Estadual Paulista - UNESP (Câmpus Marília). E-mail: selma.leticia@hotmail.com

c Doutora em Tecnologias e Sistemas de Informação pela Universidade do Minho, Portugal. Professora da Universidade Estadual Paulista - UNESP (Câmpus Marília). E-mail: rcaldas@marilia.unesp.br

d Doutor em Ciência da Informação pela Universidade de São Paulo. Professora da Universidade de São Paulo. E-mail: claudiomarcondes@ffclrp.usp.br
\end{abstract}


Rafaela Carolina Silva, Selma Letícia Capinzaiki Ottonicar, Rosângela Formentini Caldas, Cláudio Marcondes de Castro Filho

A competência em informação e o comportamento informacional dos usuários de bibliotecas híbridas: um estudo comparativo no Brasil e na Escócia

comportamento informacional para ir além do usuário. Nesse sentido, os objetivos da biblioteca vão de encontro com as necessidades informacionais dos usuários.

Descritores: Competência em informação. Comportamento informacional. Bibliotecas híbridas. Bibliotecas.

\section{INTRODUÇÃO}

A sociedade vive um paradoxo em relação à aprendizagem, pois existem cada vez mais indivíduos com dificuldades em aprender e isto gera um fracasso escolar. Concomitantemente, o período de aprendizagem aumentou por meio da educação obrigatória e, com isso, institui-se a aprendizagem ao longo da vida (POZO, 2007). Portanto, a competência em informação (Colnfo') e o comportamento informacional são duas variáveis fundamentais para viver em sociedade, exigindo das pessoas autonomia para lidar com a informação e transformá-la em conhecimento. A Colnfo pode ser incentivada pelas bibliotecas, pois são instituições sociais e culturais, além disso, são os lugares de leitura e apropriação de conhecimento, principalmente no que diz respeito à constituição do acervo e ao acesso à informação. Nesse sentido, trata-se da memória não só como o registro de um grupo social, como também no ambiente organizado para obter identidade e ideologia social, ou seja, a influência dessas instituições na coletividade de usuários, que passam a se identificar e a se comportarem em grupos sociais com características diferentes (identidade), formando ideias e agindo sobre elas (ideologia). A constituição das bibliotecas, portanto, é construída por um grupo amplo e heterogêneo de pessoas, as quais constituem a memória e a identidade social.

Uma biblioteca híbrida parte da combinação de recursos, com base em tecnologias da informação. Além disso, exige uma cultura que acolha a inovação em software, recursos e treinamento de usuários. Segundo Oppenheim e Smithson (1999), o conceito de hibridez começou com as

\footnotetext{
${ }^{1 * U t i l i z a-s e ~ o ~ t e r m o ~ c o m p e t e ̂ n c i a ~ e m ~ i n f o r m a c ̧ a ̃ o ~ e ~ s u a ~ s i g l a ~ s u g e r i d a ~ p e l o ~ d o c u m e n t o ~}$ nacional brasileiro, Carta de Marília de 2014. Disponível em: http://www.lti.pro.br/userfiles/downloads/CARTA_de_Marilia.pdf
} 
bibliotecas universitárias do Reino Unido e se espalhou por todas as bibliotecas do território (especialmente na Escócia), fossem elas públicas, escolares, especializadas ou acadêmicas. Abbott (2003) sugere que os ambientes de informação são híbridos quando trabalham com uma mistura de tecnologias como a mídia impressa e eletrônica, juntamente com programação tradicional e tecnologias baseadas na web para serviços de informática. Logo, a Colnfo, dentro das bibliotecas híbridas, auxilia os usuários a serem competentes na determinação da natureza da informação que necessitam; no acesso à informação necessária com efetividade; na avaliação interpretativa da informação e das suas fontes; no uso da informação com efetividade para alcançar um objetivo; e na compreensão das questões econômicas, legais e sociais relacionadas ao uso da informação (BELLUZZO, 2007), ou seja, influencia no comportamento informacional desses sujeitos

A partir desse contexto, o presente artigo tem como problemática a relação entre a Colnfo e o comportamento informacional, buscando entender as semelhanças e as diferenças entre seus conceitos para o desenvolvimento de comunidades em bibliotecas. Nessa perspectiva, o objetivo de pesquisa visa refletir sobre a relação da Colnfo e do comportamento informacional no contexto das bibliotecas híbridas brasileiras e do Reino Unido, mais especificamente na biblioteca da The Robert Gordon University (RGU), Aberdeen, Escócia e na Biblioteca de São Paulo - Carandiru (BSP), São Paulo, Brasil. A metodologia é de cunho qualitativo, baseada em uma pesquisa bibliográfica sobre os temas Colnfo, comportamento informacional e bibliotecas híbridas. Para realizar essa primeira etapa, buscou-se artigos de diferentes periódicos da Ciência da Informação, livros nacionais e internacionais, e documentos internacionais a respeito dos padrões $\mathrm{e}$ indicadores de competência em informação. Escolheram-se os padrões e indicadores de competência em informação da International Federation of Libraries Association (IFLA) como norteadores na construção do quadro de inter-relação, que guiou o estudo comparativo em ambas bibliotecas. Posteriormente, realizou-se um estudo comparativo entre as bibliotecas que, segundo Silva (2017), as 
Rafaela Carolina Silva, Selma Letícia Capinzaiki Ottonicar, Rosângela Formentini Caldas, Cláudio Marcondes de Castro Filho

A competência em informação e o comportamento informacional dos usuários de bibliotecas híbridas: um estudo comparativo no Brasil e na Escócia

organizações escolhidas foram as que mais se destacaram em termos de hibridez perante as bibliotecas estudadas em sua pesquisa. Nesse sentido, ressalta-se a importância deste estudo para a área da Ciência da Informação, pois ele reflete sobre localidades que discutem constantemente políticas públicas para melhoria do espaço informacional. Nessa perspectiva, a Colnfo se torna uma ferramenta essencial para que as bibliotecas híbridas alcancem seus objetivos de inclusão social e desenvolvimento de comunidades.

\section{COMPETÊNCIA EM INFORMAÇÃO}

A competência em informação foi citada pela primeira vez por Paul Zurkowski, no ano de 1974 e, a partir de então, estudos e pesquisas vêm sendo desenvolvidos para incorporar a Colnfo na vida prática das pessoas em âmbito escolar, gerencial e social. Lloyd (2017) explica que a Colnfo capacita o indivíduo a compreender as fontes em informação e a interpretar os saberes de modo que ele desenvolva sua capacidade de pensamento crítico em relação à informação. A prática dessa competência é complexa, pois possui dimensões relacionais, situacionais, recursivas e incorporadas. Além disso, ela tem se tornado fundamental no contexto da "pós verdade"2, pois contribui para a avaliação crítica das informações. A Association of College and Research Libraries (ACRL, 2015) complementa as afirmações de Lloyd (2017) ao apontar que a competência em informação envolve um conjunto de habilidades que desenvolvem a reflexão a respeito da informação, assim como a compreensão da maneira pela qual a informação é produzida e valorizada. O objetivo dessa competência é o uso da informação, principalmente no que tange à criação de novos conhecimentos e à participação ética nas comunidades de aprendizagem. Ressalta-se que, além das comunidades de aprendizagem,

\footnotetext{
${ }^{2 *}$ Essa definição foi adicionada ao dicionário Oxford no Reino Unido em 2016 para se referir a fatos ou informações que tem como objetivo causar um apelo emocional no público. A emoção que causa nas pessoas é mais importante que os fatos reais. Informações Disponíveis em: https://www.cartacapital.com.br/revista/933/a-era-da-pos-verdade
} 
Rafaela Carolina Silva, Selma Letícia Capinzaiki Ottonicar, Rosângela Formentini Caldas, Cláudio Marcondes de Castro Filho

A competência em informação e o comportamento informacional dos usuários de bibliotecas híbridas: um estudo comparativo no Brasil e na Escócia

como aquelas formadas nas universidades e bibliotecas, a Colnfo contribui com as pessoas ao longo da vida e em todos os seus contextos.

As bibliotecas contribuem e influenciam a sociedade à medida que auxiliam os usuários a atuar com respeito a sustentabilidade. Nessa perspectiva, a Colnfo não está voltada apenas para a capacitação de profissionais, mas para que as pessoas sejam atores em toda a sua vida, deixando de receber as informações de forma passiva, interpretando e refletindo sobre as informações que recebem. A educação de usuários está voltada, na maioria das vezes, no processo de busca de informação como um método cognitivo ou comportamental. Então, frequentemente as pesquisas práticas sobre a competência em informação estão relacionadas com a informação digital. Nesse contexto, há uma competição entre os filtros de qualidade tradicionais contra as novas formas de controle de qualidade de informação (LIMBERG; SUNDIN; TALJA, 2013). Entretanto, não se pode esquecer que são os indivíduos que avaliam e constroem o conhecimento, conforme expõe Lwoga (2014), ao defender que a Colnfo contribui para que os estudantes de graduação sejam hábeis e gerenciem suas pesquisas e aprendizagem. Nesse sentido, ela é fundamental para que os discentes possam desenvolver habilidades ao longo da vida. A teoria demonstra que a Colnfo gera consequências tanto na vida acadêmica do aluno quanto na vida pessoal.

Gomes e Dumond (2016) ilustram que a Colnfo possui uma dimensão cognitiva e social. Ela estimula a busca, o acesso, o uso e a comunicação da informação de modo ético, a fim de que o conhecimento seja fundado individualmente ou em grupo. Várias organizações de bibliotecários têm se preocupado com o tema da Colnfo e compartilhado documentos escritos por especialistas da área. Nesses documentos são discutidos os conceitos da Colnfo para vários contextos, assim como as ações de pesquisadores e de bibliotecas para implementar a temática na vida social. Dentre eles, destaca-se a IFLA, que tem contribuído para a disseminação e para a conscientização sobre o tema. Em 2007, juntamente com a UNESCO, a IFLA criou um 
documento redigido por Lau (2007), a fim de orientar a criação desses padrões e indicadores conforme o Quadro I (Anexo I). Os padrões da IFLA se baseiam em três dimensões: o acesso, a avaliação e o uso da informação. No acesso, o primeiro padrão aponta para a necessidade de informação do indivíduo, ou seja, quando percebe que precisa de obter determinado dado ou informação para completar uma tarefa. O segundo padrão demonstra o processo de busca da informação em fontes potenciais. $\mathrm{Na}$ avaliação, o padrão 1 indica que o usuário avalia a informação de maneira crítica e competente e, assim, conforme indica o padrão 2 , organiza informação para utiliza-la no presente e no futuro. Por fim, a dimensão do uso indica que o usuário aplica/usa a informação de maneira precisa e criativa, além disso comunica a informação de maneira ética.

Lau (2007) dividiu as etapas principais da Colnfo, que estão presentes em seus conceitos, o acesso, a avaliação e o uso da informação. Cada fase possui dois padrões e os resultados desejáveis. Ao observar o quadro, inferese que, ao acessar a informação, o indivíduo precisa, a priori, perceber sua necessidade de informação e, em seguida, localizar essa informação, buscando e selecionando as várias fontes potenciais. Nesse sentido, faz-se necessário que as bibliotecas, principalmente as consideradas híbridas, valorizem a aprendizagem ao longo da vida, na medida em que influenciam os usuários a utilizarem técnicas de busca, avaliação e uso da informação, interferindo, assim, no seu comportamento informacional. Portanto, com a competência em informação, novas portas se abrem perante as exigências da sociedade, principalmente no final do século XX. Assim, surgem novos modelos voltados ao alcance da maturidade informacional, pois as pessoas precisam saber como recuperar, utilizar e disseminar a informação de maneira eficaz (AGUIAR, 2017).

\section{COMPORTAMENTO INFORMACIONAL}

Wilson (1999) definiu o termo 'comportamento informacional' para ser inserido na área de comportamento humano, referindo-se à maneira pela qual 
o indivíduo busca, usa e compartilha informação quando alguém percebe sua própria necessidade de informação. Assim, em 2000, publicou um artigo explicando o comportamento informacional e mais outros três tipos de comportamentos derivados dele: comportamento de busca da informação, comportamento de pesquisa de informação, e comportamento de uso de informação (GASQUE, COSTA, 2010, p.22). Wilson (1999) criticava pesquisas que possuíam tendências positivistas, já que, para ele, os estudos de usuários estavam focados em uma metodologia quantitativa, medindo-se a quantidade de visitas à unidade de informação, número de citações em artigos, entre outros (PIRES, 2012).

As autoras Gasque e Costa defendem que o comportamento informacional (2010, p.31-32) é entendido como um processo natural das pessoas enquanto aprendizes da vida, não obstante, demanda uma compreensão ampla por parte do pesquisador. Esse comportamento exige a compreensão das atividades de busca, uso e compartilhamento de informação. Tais atividades são realizadas pelo ser humano quando ele necessita de informação. Nessa perspectiva, segundo Araújo (2016, p.63), o comportamento informacional tem origem numa situação problemática, sendo esse "[...] 0 mecanismo ativador das ações de busca por informação, elemento determinante do processo, pois é a partir dela que o sujeito se engaja no processo de busca que resultará no encontro e uso da informação". $\mathrm{Na}$ mesma linha de pensamento de Araújo (2016), Malaquias et al. (2017) explicam que o comportamento informacional auxilia os usuários a identificar as principais fontes de pesquisa, evidenciando suas limitações e necessidades informacionais. Complementando as ideias de Araújo (2016) e de Malaquias et al. (2017), Silva (2013) descreve que o conceitos cruciais a serem considerados quando se estuda o comportamento informacional são: a infocomunicação (humana e social) na realidade dentro de situações concretas, contextos precisos e respetivo meio ambiente. $O$ foco do comportamento informacional, então, está na solução da necessidade de informação por meio das ações de busca, uso e compartilhamento, ou seja, a necessidade é 
transformada em ações concretas em determinado contexto. Sendo assim, não pode estar somente associado com a busca de informação e, por isso, envolve o uso da informação obtida e da comunicação dessa informação.

O comportamento informacional não é baseado na disponibilidade dos recursos, mas nos processos cognitivos dos indivíduos. Ressalta-se que o contexto também influencia este comportamento, principalmente no que tange à percepção da necessidade de informação, a seleção da fonte de informação e a decisão de acessar a informação (MARTíNEZ-SILVEIRA; ODDONE, 2007). De acordo com Wilson (1996) o conceito de necessidade é psicológico, porque remete a um estado mental. A necessidade é subjetiva, e a motivação para supri-la advém dos impulsos psíquicos. $\mathrm{Na}$ literatura, existem diferentes modelos de comportamento informacional propostos, dentre eles, destaca-se o Information Search Process (ISP), de Carol Kuthlau (1991), e o modelo de Tom Wilson, criado em 1981 e nomeado 'Áreas da pesquisa do comportamento informacional'. O processo de busca depende de fatores externos, que são as "ações comuns a cada estágio", e depende de fatores internos, como o 'sentimento comum a cada estágio' e os 'pensamentos comuns a cada estágio'. Percebe-se que a etapa da necessidade gera um comportamento de busca informacional que, consequentemente, ocorre por meio de três ações do sujeito, a demanda por sistemas de informação, na qual se exige habilidades e capacidades para manusear determinada tecnologia, a demanda por outras fontes de informação, ou seja, o indivíduo analisa diversas fontes informacionais que podem ser analógicas e digitais. Para tanto, é preciso estar atento à qualidade e à confiabilidade delas, e na etapa de troca de informação ocorre de maneira formal e informal, e atualmente, utiliza-se a palavra compartilhamento, pois os indivíduos disseminam a informação para várias pessoas e ao mesmo tempo são receptores de informação. A obtenção da informação pode gerar satisfação ou insatisfação, dependendo da necessidade do indivíduo e com isso reinicia-se o processo de busca informacional. Pires (2012) explica que o processo de identificação da necessidade de informação se repete e o usuário pode encontrar alternativas depois da primeira tentativa. 
Ainda que uma necessidade seja suprida, outras necessidades irão surgir, continuando o ciclo do comportamento informacional em um fluxo constante. Nesse processo, segundo Silvia (2008, p.160), além de considerar o insucesso, é importante levar em conta que existem outros fatores que também comprometem o comportamento do usuário, como "[...] a habilidade técnica específica desse usuário, influenciando diretamente na utilização dos sistemas, assim como o contexto e o espaço onde a pessoa desenvolve o uso". Por isso, a biblioteca híbrida pode contribuir no processo de uso da informação do indivíduo, sendo fundamental para a aprendizagem.

\section{BIBLIOTECAS HÍBRIDAS: A BSP E A BIBLIOTECA DA THE ROBERT GORDON UNIVERSITY}

A trajetória do desenvolvimento das bibliotecas híbridas começou no Reino Unido, em 1992, com a abolição da "divisão binária" entre as velhas universidades e os cursos politécnicos, o que impactou no uso dessas novas bibliotecas para a qualidade das pesquisas. Segundo Russell, Gardner e Miller (1999), os requisitos básicos de uma biblioteca híbrida são: providência de serviços para descoberta, localização, requisição, envio/entrega e utilização dos recursos; o fornecimento de serviços deve ser consistente, para recursos locais ou remotos, independentemente do tipo de seu suporte; a estrutura organizacional deve ser flexível, proporcionando o desenvolvimento de novos sistemas quando necessário; os sistemas devem basear-se em normas internacionais, propiciando o aumento do volume e o tráfego de recursos. Dewe (2016) concluiu que há uma relação positiva significativa entre as atitudes pessoais dos profissionais, os ambientes híbridos e sua subsequente tomada de decisão em meio social, explicando que as bibliotecas públicas podem ser caracterizadas normalmente como um serviço que é estabelecido, apoiado e financiado pela comunidade. A ideia parte de uma visão extensionista do conceito de bibliotecas, nas quais, por meio do conhecimento construído, exige-se o exercício da cidadania. Logo, tais ambientes requerem uma visão cética, isto é, nem tudo que é eletrônico é bom, e nem tudo o que 
está em um meio tradicional é necessariamente antiquado. Por outro lado, exigem uma visão subjetiva em se tratando dos sujeitos que se relacionam com a instituição, estudando os aspectos motivacionais e inclusivos que tornam o indivíduo cidadão: arquitetura, serviços e produtos oferecidos, relações sociais, design da informação, convergência de linguagens, bem como o aprender a aprender ao longo da vida. São necessários dois novos conjuntos de habilidades a serem utilizados em ambientes híbridos: um deles é saber administrar o sistema de gestão de bibliotecas, configurando o cenário para trabalhar com novas informações e criar estruturas adequadas ao seu uso; o outro é o trabalho de manutenção de sistemas voltados para a eficiência e eficácia dos produtos e serviços oferecidos pela instituição (GARCEZ; RADOS, 2002). Nesse sentido, tanto a biblioteca híbrida interfere no desenvolvimento de comunidades quanto as comunidades interferem no trabalho da biblioteca.

Em termos práticos, a biblioteca da The Robert Gordon University voltase à pesquisa acadêmica dos alunos de sua universidade, Aberdeen, Escócia, possuindo, dentre outros serviços, plataformas de atendimento online (RGU.AC.UK, 2016). Ressalta-se que a universidade é reconhecida internacionalmente pela excelência em suas pesquisas, e essas não se limitam à totalidade da universidade, chegando à comunidade via internet $\mathrm{e}$ publicações em jornais. A biblioteca da universidade trabalha com a comunidade no sentido de incluí-las não somente em suas atividades, mas também em sociedade, por meio da acessibilidade e das atividades de pesquisa e entretenimento. Nessa biblioteca, a hibridez é implementada: (1) por meio da sintonia com as ações governamentais de cada Conselho; (2) pela arquitetura da instituição; (3) pelas informações disponibilizadas para acesso, independentemente do suporte ou mídia; (4) pela atualização frequente do acervo; (5) pelo trabalho em equipe e com profissionais de diferentes áreas do conhecimento, que estudam a comunidade a fim de atender às diferentes necessidades dos usuários; (6) pelo desenvolvimento de atividades de outras instituições em sua estrutura organizacional; (7) por se caracterizar como lugar de entretenimento familiar, pesquisa e readaptação de pessoas; (8 ) por 
Rafaela Carolina Silva, Selma Letícia Capinzaiki Ottonicar, Rosângela Formentini Caldas, Cláudio Marcondes de Castro Filho

A competência em informação e o comportamento informacional dos usuários de bibliotecas híbridas: um estudo comparativo no Brasil e na Escócia

oferecer capacitação de funcionários e de usuários nos aspectos relacionados ao acesso e uso da informação; e (9 ) pelo atendimento presencial ou não.

Em relação à BSP, a hibridez ocorre por meio: (1) de práticas internacionais (Biblioteca de Santiago, Chile); (2) da sintonia com as ações governamentais do Brasil; (3) dos espaços arrojados, possuindo projeto inovador de inclusão social por meio da leitura (a estrutura de ambas as instituições foi planejada para oferecer conforto, autonomia e atenção aos sócios e frequentadores, que são o elemento central da biblioteca); (4) da revitalização dos prédios (antes antiga Casa de Detenção Carandiru, na BSP); (5) das informações disponíveis em variados tipos de suporte e mídia (oferecem conteúdo em formatos variados, como livros tradicionais ou em formatos acessíveis (braille, audiolivro), Klindles, DVDs, CDs, além de jogos); (6) da ambientação que oferece ao público um espaço acolhedor e aconchegante, como convite para a leitura; da sociedade, que pode contribuir na escolha de itens a serem adquiridos para o acervo; (7) dos acervos atualizados frequentemente (o grande foco é a literatura nacional e internacional; os assuntos complementares são das áreas de Filosofia, Religião, Autoajuda, Esportes, Biografias, História, entre outras).

Sendo assim, para que as bibliotecas sejam consideradas híbridas torna-se necessário levar em conta alguns elementos-chave de maneira constante. Por exemplo, a melhoria futura, funcionários, usuários, coleção, design interno, design externo, gerenciamento local da informação e gerenciamento externo da informação - todas atividades relacionadas com a Colnfo. Em relação ao item melhoria contínua, esse se refere a projetos futuros, como eventos, workshops, cursos, dentre outros, buscando a elaboração de uma agenda de trabalho que preze pela programação dessas atividades, o que inclui. No que se refere aos funcionários, é importante destacar o treinamento de funcionários, o desenvolvimento de carreiras e a educação ao longo da vida, também prezadas pela Colnfo. No que diz respeito aos usuários, é necessário que a biblioteca realize treinamentos para os 
mesmos, ofereça serviços e produtos que envolvam a comunidade como um todo, em conjunto com a educação ao longo da vida. A natureza da coleção deve ser levada em conta, assim como o seu compartilhamento, suportes informacionais oferecidos, formas de aquisição, acesso aberto a bases de dados e de quais bases de dados a biblioteca faz parte. No design interno necessita-se trabalhar as possibilidades de inclusão social, infraestrutura local, espaços especiais e acessibilidade ao público. De outra maneira, no design externo precisa ser estudada a arquitetura da informação do local em relação aos seus parceiros e comunidade.

\section{METODOLOGIA}

O presente trabalho é de natureza qualitativa e conta com uma pesquisa bibliográfica para explicar e construir conceitos sobre a Colnfo e o comportamento informacional, além de dar suporte à discussão e à interrelação dos temas. Esse tipo de pesquisa, de acordo com Lima e Mioto (2007), é um procedimento metodológico importante na produção do conhecimento científico, pois contribui para criar novas ideias a partir de temas pouco explorados que servem a pesquisas futuras. Para a análise e escolha das bibliotecas estudadas, utilizou-se o método comparativo do Estudo de Casos Múltiplos. Como descreve Yin (2010), o Estudo de Casos Múltiplos contribui para uma abordagem adequada, pois proporciona contestar e contrastar as respostas obtidas de modo parcial. Pretendeu-se, portanto, contrastar os significados e os diferentes conceitos de competência em informação e de comportamento informacional em bibliotecas híbridas nacionais e internacionais, visando conhecer características comuns e divergentes na atuação do profissional da informação em ambientes híbridos.

Assim, para compreender melhor o objeto dos fenômenos investigados, a pesquisa buscou um mapeamento das características dos espaços informacionais híbridos que, posteriormente comparados aos procedimentos da Colnfo, propiciaram o alcance do objetivo dessa pesquisa. A Análise de Conteúdo caracterizou-se como um recurso metodológico, utilizado para 
Rafaela Carolina Silva, Selma Letícia Capinzaiki Ottonicar, Rosângela Formentini Caldas, Cláudio Marcondes de Castro Filho

A competência em informação e o comportamento informacional dos usuários de bibliotecas híbridas: um estudo comparativo no Brasil e na Escócia

levantar os indicadores de impacto que nortearam os aspectos a serem comparados, no Estudo de Casos Múltiplos das bibliotecas híbridas abarcadas nesta pesquisa.

Para a fase inicial da coleta de dados foram elaboradas entrevistas, questionários e observações participativas. Nos instrumentos de entrevista e questionário utilizou-se o referencial bibliográfico de Russel, Gardner e Miller (1999), Oppenheim e Smithson (1999) e Garcez e Rados (2002), pois eles refletem os indicadores de Análise de Conteúdo expostos nesta pesquisa. $O$ roteiro das entrevistas partiu de categorias ligadas à contribuição das bibliotecas para a formação de pessoas inseridas em sociedade. A entrevista aplicada na BSP possuía 19 (dezenove), já no cenário do Reino Unido, 16 (dezesseis) questões. Por entender que se tratava de contextos com culturas diferenciadas, em um primeiro momento, as características de análise foram separadas para a BSP e para a biblioteca da RGU, para que depois fosse possível realizar o comparativo. Daí decorre a diferença no número de perguntas de cada entrevista, que foram desenvolvidos conforme a orientação dos pesquisadores de cada localidade.

\section{RESULTADOS E DISCUSSÕES}

A biblioteca da Robert Gordon University foi inaugurada em 2013 e está localizada no Edifício Sir Lan Wood, no sudoeste da cidade de Aberdeen, Escócia. Possui 34.000 metros quadrados e abriga todos os departamentos acadêmicos da universidade. O design da biblioteca é arrojado, na medida em que seu prédio é todo de vidro, captando a luz do sol como fonte de energia alternativa e propiciando que os usuários estudem com a vista da natureza que cerca o redor. A biblioteca começa no terceiro andar e vai até o oitavo andar do prédio. A coleção impressa é quase a mesma que a das cópias digitais, pois quase toda a coleção impressa é digitalizada, estando, também, disponível na coleção eletrônica. Apenas estudantes e funcionários da universidade (incluindo alunos à distância) podem acessar a base de dados em rede ou pegar livros emprestados. Pessoas externas só podem ver os bancos de dados 
on-line e acessar a coleção visitando-a pessoalmente, a não ser que façam um plano de pagamento anual para ter acesso ao acervo. Em relação às empresas, se elas forem parceiras da universidade, o acesso se torna gratuito. Para ter sua presença nas mídias sociais e aumentar o contato com os alunos, a biblioteca tem um Facebook e uma conta no Twitter, além do seu website.

A BSP foi inaugurada em 8 de fevereiro de 2010, com o objetivo de incentivar e promover o gosto pela leitura. Está situada na Zona Norte da capital de São Paulo. Sua estrutura foi planejada para oferecer conforto, autonomia e atenção aos seus sócios e frequentadores. Ocupa uma área de 4.257 metros, dividindo-se entre o piso térreo e o piso superior, para atender crianças, jovens, adultos e idosos com e sem deficiência. A biblioteca conta com recursos tecnológicos e oferece aos seus usuários microcomputadores, rede wireless e terminal de autoatendimento (BSP.ORG.BR, 2016). No que se refere ao maquinário, dispõe de: máquinas de auto empréstimo; tapetes no chão para deficientes físicos; equipamentos especiais para deficientes auditivos; jogos adaptados para pessoas com deficiência visual, auditiva e motora. Para a acessibilidade, máquina ampliadora (aparelho que amplia as letras dos livros e separa-as de acordo com as necessidades de tons de cores de pessoas que têm baixa visão), máquina termofusora (faz decalque (alto relevo) da folha com o objetivo de facilitar a leitura tátil para deficientes visuais); máquina Vitor Hugo (faz a leitura dos livros falados e audiolivros); máquina CPCD (para deficiência visual); máquina Plus Tech (leitora de livros- coloca-se o livro posicionado, aperta-se o botão escanear e a máquina começa a contar a história - o áudio sai por meio do fone de ouvido); computadores adaptados para pessoas com baixa visão e baixa mobilidade (teclado com letras maiores e cores chamativas, mouse diferenciado); máquina Folheadora (para pessoas com baixa mobilidade); máquina Point (leitora de livros - coloca-se o livro posicionado, aperta-se botão escanear e a máquina começa a contar a história - o áudio sai sem o fone de ouvido); mesa reguladora (sobe, desce, controla e vira as páginas dos livros). 
A escolha do Modelo de Comportamento Informacional de Wilson ocorreu devido ao fato de que ele é considerado um clássico na literatura da área, representando as principais etapas do comportamento de busca. Buscouse relacionar esse modelo com os padrões e indicadores de competência em informação divulgados pela IFLA (2007) por serem considerados como internacionais, portanto se aplicam no estudo comparativo de bibliotecas de duas nações distintas. A partir da inter-relação teórica, elaborou-se o Quadro II (Anexo II), que demonstra como os serviços das bibliotecas híbridas analisadas podem contribuir com o desenvolvimento da competência em informação, bem como do comportamento informacional nessas instituições. A partir do Quadro II, foi possível estabelecer uma discussão entre o comportamento informacional e a Colnfo, de modo a contribuir com ambas áreas do conhecimento e demonstrar que se complementam. Não obstante, relacionaram-se as etapas de ambos os temas com as atividades desenvolvidas nas bibliotecas por meio do estudo caso múltiplo, organizando a comparação dos resultados. A necessidade de informação ocorre quando o indivíduo percebe que precisa de determinada informação (WILSON, 1981; IFLA, 2007; BELLUZZO, 2007). Nessa etapa, há uma angústia para realizar este processo (KULTHAU, 1991). Além disso, é importante verificar a extensão dessa necessidade, ou seja, se é uma informação simples ou complexa.

A biblioteca RGU oferece visitas técnicas ao local, ensinando aos usuários como usar suas bases de dados, realizar pesquisas, assim como utilizar o sistema da biblioteca, no início de cada ano acadêmico. Quando um usuário tem alguma dúvida específica vai pessoalmente até a biblioteca ou mandar e-mail, informando suas dúvidas. Esse comportamento se enquadra com a primeira linha do Quadro II, pois a pessoa competente em informação percebe a necessidade de informação (IFLA, 2007; BELLUZZO, 2007) e, portanto, envolve o primeiro nível do comportamento informacional, definido por Wilson (1981) como o da necessidade. Uma vez vista a necessidade de informação, a pessoa se engaja no acesso à informação e demanda sistemas de informação (WILSON, 1981) que podem estar explicitados em diferentes 
formatos, como livros, computadores, tablets, jornais, revistas, entre outros. Nesse momento, é importante saber como utilizar as TIC e a mídia a seu favor, bem como estabelecer uma estratégia de busca (IFLA, 2007; BELLUZZO, 2007).

Após buscar as informações, a pessoa verifica se estas são completas e suficientes para solucionar o seu problema (WILSON, 1981; IFLA, 2007). Caso contrário, realiza um novo acesso e se atenta às fontes de informação e à sua confiabilidade (BELLUZZO, 2007). Nesta etapa, uma desinformação ou informação incorreta poderá determinar o sucesso ou fracasso do processo de busca informacional. No que se refere aos padrões da IFLA, as ações da biblioteca da RGU envolvem capacitar os usuários para acessarem e usarem a informação que procuram de maneira útil. Nesse sentido, são trabalhadas as capacidades dos usuários de modo que eles se reconheçam perante 0 contexto social e o ambiente tecnológico da instituição. É possível observar essa preocupação da biblioteca híbrida em questão na descrição dos demais produtos e serviços oferecidos (mencionados nos próximos parágrafos). Além disso, os usuários precisam saber como acessar a tecnologia para realizar atividades da biblioteca, pois tanto o empréstimo como a devolução de livros são feitos pelo próprio usuário, via sistema da biblioteca e máquinas de autoempréstimo. Caso haja alguma dúvida, há sempre um funcionário de plantão para auxiliá-lo.

A informação via eletrônica, na BSP, é feita pelo site institucional e por meio das redes sociais, que possuem informações acerca das políticas e atividades das bibliotecas. Além disso, o site disponibiliza livros eletrônicos gratuitos e acesso ao catálogo de outras bibliotecas virtuais, a saber: a Biblioteca Digital Mundial, a Biblioteca do Congresso dos Estados Unidos da América, a ebooksBrasil, a Enciclopédia Britânica, a SciELO Livros, a Biblioteca Virtual da América Latina, a Biblioteca Virtual do Governo do Estado, a Biblioteca Brasiliana Guita e José Mindlin, a Children's Library e a Dorinateca - Biblioteca Digital Dorina Nowill. Logo, além da competência em tecnologias, é possível observar que tais itens abarcam a numeracia e a literacia para a 
resolução de problemas. Em relação ao software inovativo, a novidade está relacionada à oportunidade de contato direto da BSP com a empresa desenvolvedora do software, por meio de relatórios de experiências sugerindo melhorias. Há também um software que faz leitura de tela (acessibilidade). Já a biblioteca híbrida RGU investe na aprendizagem a distancia a fim de que outras pessoas possam realizar os seus cursos, inclusive de como realizar pesquisas em banco de dados eletrônicos. Fornece serviços de impressão para aqueles que necessitam acessar as informações de maneira analógica, fotocópia e digitalização de documentos. Tanto o empréstimo como a devolução de livros são feitos pelo próprio usuário, via sistema da biblioteca e máquinas de autoempréstimo. Caso haja alguma dúvida, há sempre um funcionário de plantão para auxiliá-lo. O usuário deve fazer log-in no wi-fi pela primeira vez, mas, posteriormente o log-in será automático. A universidade promove uma rede livre de internet, disponível também para usuários externos, mas, para esses últimos, a rede é limitada, e os usuários não podem entrar nas bases de dados da biblioteca, que são bloqueadas. As universidades e as bibliotecas na Escócia são muito colaborativas, fazendo parte da Confederação Escocesa de Bibliotecas Universitárias e de Pesquisa (SCURL). Nesta rede, todas as universidades da Escócia trabalham em conjunto e partilham materiais e, por conseguinte, reduzem seus custos, bem como fornecem formação e especialização a funcionários. Nesse sentido, a biblioteca da RGU realiza reuniões locais com a rede pelo menos três vezes por ano, a fim de obter feedback dos estudantes em âmbito britânico. A instituição tem um formulário on-line para pedido de livros a serem comprados, e as sugestões podem advir de todos os membros da universidade. A instituição aceita doações, mas somente de materiais úteis para a sua comunidade de usuários na biblioteca, como é o caso de livros acadêmicos relevantes. A biblioteca é um ambiente tranquilo para estudos, mas também conta com espaços para entretenimento, como a recepção, que tem jornais e sofás coloridos, espalhados pelo andar. Os alunos são questionadores, não hesitam em procurar a biblioteca em busca de suas necessidades e desejos e em analisar, criticamente, os produtos e 
serviços oferecidos pela unidade. A biblioteca oferece serviços para construir uma ligação entre as necessidades do usuário e a coleção da biblioteca, juntando-se ao Centro de Aprendizagem, que fornece guias aos usuários e materiais educacionais.

Sendo assim, ambas bibliotecas valorizam a competência em informação na questão do uso das tecnologias, nas infraestruturas de rede de compartilhamento e interação entre indivíduos por meio das Tecnologias de Informação e de Comunicação. Desse modo, parte de uma valorização das TIC, principalmente, pela pressão instituída pela convergência das mídias, tecnologias e pessoas, com vistas à cultura digital em que a Escócia e o Brasil vivenciam. Conforme explica Limberg, Sundin e Talja (2013), o processo de busca de informação é cognitivo e comportamental e, por isso, as pesquisas sobre a Colnfo também se atentam a questão da informação digital. Tais ações, voltadas ao acesso à informação por meio da tecnologia, estão de acordo com o comportamento informacional, na medida em que há uma demanda por Sistemas de Informação (WILCON, 1981) e a pessoa competente em informação identifica e avalia as fontes potenciais de informação; desenvolve estratégias de busca; acessa fontes de informação selecionadas; e seleciona e recupera a informação (IFLA, 2007). Ao realizar o processo de compartilhamento da informação (WILSON, 1981,) o usuário busca novas formas de comunicar, apresentar e usar a informação; aplica a informação recuperada. Além disso, apreende ou internaliza a informação como conhecimento pessoal e apresenta o produto da informação (IFLA, 2007).

Limberg, Sundin e Talja (2013) apontam que a Colnfo é modelada e modela as práticas. $O$ ensino e a aprendizagem, a respeito do processo de busca e uso de informação, valorizam a identificação e a compreensão das capacidades dos indivíduos. Na questão do uso da informação, a biblioteca híbrida RGU oferece a possibilidade de exposição de obras dos usuários no espaço da biblioteca. Ao permitir a exposição da obra de arte, a organização demonstra que o uso literário ou artístico da informação é valorizado e importante, estimulando a produção de obras por parte de seus usuários. 
Assim os indivíduos não são apenas consumidores de informação, mas produtores de novas ideias. Além disso, a RGU troca de dados com outras bibliotecas de outras universidades do Reino Unido, compartilhando a informação para que usuários de diferentes cidades possam ter acesso. Assim estimula o uso da informação em toda a região do Reino Unido. Realiza a leitura em grupo a fim de que os conhecimentos dos leitores sejam compartilhados, pois o ato é de ler pode ser muito solitário e os usuários podem aprender por meio dos demais leitores. Incentiva a leitura individual a fim de usar a informação e transformá-la em auto- conhecimento.

A BSP assim como a RGU realiza atividades de leitura em grupo a fim de que o uso da informação seja compartilhado entre as pessoas e construam conhecimento coletivo. Também favorece a leitura individual para que $o$ indivíduo aprenda a aprender. Estimula diferentes formas de busca da informação e incentiva grupos de pesquisa, a fim de que possam acessar a informação e utilizá-la em conjunto. Ao usar a informação e tomar a decisão, as informações acabam sendo disseminadas em um grupo de indivíduos que estão envolvidos com o acesso para alcançar um objetivo específico com efetividade. Nesta fase, pode ocorrer uma análise do processo pelo sujeito a partir do sucesso ou fracasso. É nesse momento que Wilson (1981) trata da satisfação e insatisfação com o resultado de sua própria aprendizagem. Assim, a satisfação e a insatisfação propostas por Wilson (1981) são modos de avaliação na construção do conhecimento, conforme explica Lloyd (2017) a Colnfo é um conjunto de atividades e capacidades estruturadas e apropriadas relevantes em um contexto. Defende-se que a satisfação ou insatisfação do indivíduo reflete o resultado da busca de informação e a percepção da utilidade do conhecimento construído para uma situação específica. No último momento, existe a compreensão das consequências do alcance da meta desejada, consequências essas que podem ser econômicas, políticas ou legais (WILSON, 1981; IFLA, 2007), respeitando-se os direitos de propriedade intelectual e usando a informação com responsabilidade (BELLUZZO, 2007). É no final do processo que o indivíduo percebe se ficou satisfeito. A insatisfação 
estimula o reinício do ciclo e o diagnóstico das falhas, contribuindo para que o indivíduo realize o feedback. Nesse momento o individuo satisfeito saberá comunicar a informação de maneira ética com reconhecimento da propriedade intelectual (IFLA, 2007), compreender o uso ético e legal da informação. Não obstante, sabe como comunicar o produto da informação, os meios pelos quais pode se utilizar para atingir o publico e também usa os padrões e indicadores para o reconhecimento da informação. Duarte e Caldin (2016) tratam da dimensão estética da Colnfo, que é a prática do indivíduo mostrar seu talento por meio da expressão artística, se utilizando das concepções do belo e da beleza. Nesse caso, a pessoa faz parte de um exercício estético da Colnfo, assim como aplica seus conhecimentos nas práticas do dia a dia. O valor da informação é norteado perante a necessidade do contexto e se manifesta nas publicações, acesso a informação, mercantilização das informações pessoais, bem como na propriedade intelectual. Portanto, a compreensão do valor da informação, em um ambiente onde as informações são gratuitas pode ser mais difícil. Geralmente, nesses contextos o indivíduo tem seu primeiro contato com a ideia de propriedade intelectual por meio das normas de citação e do plágio (ACRL, 2015).

Além dessas atividades, a BSP leva atividades de leitura e de divulgação local até instituições carentes, asilos, hospitais, escolas, em conjunto com o serviço social. Se a pessoa não consegue ir até a biblioteca, leva-se atividades de mais ou menos uma hora e meia para a instituição, ou seja, são destacados aqui os itens do Quadro II que abarcarem a competência em informação e o comportamento informacional propostos pelo Quadro II. O intuito é trazer, posteriormente, os sócios que tiverem a possibilidade de ir até a biblioteca para o local, buscando a formação do hábito da leitura, como meio de uso da informação e construção de conhecimento social. A biblioteca, também conta com o serviço social, uma ação considerada como inovadora. O trabalho começa no reconhecimento do entorno da biblioteca pelos assistentes sociais, para entender o que é e como atuar na instituição. Posteriormente, o foco é trabalhar o público, seus conflitos, os conflitos entre eles e em relação à 
instituição, o que envolve saber a satisfação ou insatisfação da comunidade em relação aos serviços oferecidos pela biblioteca.

As atividades desenvolvidas pelas bibliotecas estão relacionadas, portanto, estimulam as competências e habilidades humanas em lidar com a informação de maneira autônoma. Preza-se, portanto, por uma pluralidade de protagonistas sociais na construção contínua de conhecimentos compartilhados. Logo, envolvem o todos os níveis do comportamento informacional definidos por Wilson (1981). No âmbito dos padrões da IFLA, ambas bibliotecas trabalham a literacia $^{3}$, a numeracia ${ }^{4}$, a resolução de problemas e a literacia em tecnologia para tornarem o comportamento dos usuários à nível de pessoas competentes em informação. Por fim, entende-se ser essa é a proposta das bibliotecas híbridas perante o desenvolvimento de suas comunidades. Nessa perspectiva, o comportamento informacional e a Colnfo são assuntos que se complementam e não podem existir sem o outro. A Colnfo envolve, dentre outros fatores, as atitudes e as ações que se concretizam, por meio do comportamento de busca, acesso e uso da informação. Defende-se, então, que não existe uma superioridade entre a Colnfo e o comportamento informacional, pois, ambos se complementam, havendo uma linha tênue em sua diferenciação. Assim, faz-se necessário utilizar quadros, figuras e mapas conceituais, a fim de contribuir com o comportamento informacional dos indivíduos para que se tornem competentes em informação e aprendam ao longo da vida.

\section{CONSIDERAÇÕES FINAIS}

A partir das discussões do trabalho foi possível defender que, apesar da Colnfo e do comportamento informacional serem pesquisados separadamente, existe uma integração entre eles. Tal relação pode ser observada na contribuição de ambas áreas, nas quais não existe uma superioridade.

\footnotetext{
$3^{\star}$ Questão da leitura e interpretação de textos.

${ }^{4 *}$ Resolução de problemas matemáticos.
} 
Entende-se que a biblioteca híbrida deve possuir um diálogo pleno com a sociedade, a fim de adequar-se ao desenvolvimento de um ambiente de inclusão e de crescimento organizacional, colaborando para a formação de cidadãos críticos, que valorizem a biblioteca em sua constituição. Desse modo, as bibliotecas, como equipamentos híbridos, corroboram para as ações culturais, educacionais e de acolhimento das comunidades de seu entorno.

Ainda que de maneiras diferentes, as bibliotecas híbridas BSP e da RGU possuem preocupação com a questão do comportamento informacional e da Colnfo. As bibliotecas em questão realizam seus esforços para que os usuários sejam aprendizes ao longo da vida. Além do mais, as bibliotecas híbridas valorizam o comportamento informacional dos usuários, voltando seus serviços e produtos ao acesso e ao uso da informação para construir conhecimento de maneira eficaz. Isso acontece porque não só disponibilizam recursos digitais modernos, mas promovem a capacitação dos indivíduos. Entretanto, a tecnologia atual não é o foco da biblioteca, de fato é vista como um suporte e apoio, o foco está na aprendizagem do usuário para se tornar um cidadão que obedece às questões éticas e as leis que regem o uso da informação para a construção de conhecimento, ou seja, indivíduos competentes em informação.

\section{REFERÊNCIAS}

ABBOT, C. Hybrid information management: skills for a senior staff. Birmingham: University of Birmingham, 2003.

AGUIAR, N. C. de. A contribuição teórica de Kelley Cristine Gonçalves Dias Gasque para o discurso da competência informacional no Brasil. Ciência da Informação, Maceió, v. 4, n. 1, p. 17-27, jan./abr. 2017. Disponível em: $<$ http://www.seer.ufal.br/index.php/cir/article/view/2860/2446>. Acesso em: 05 ago. 2017.

ARAÚJO, A. C. A. Estudos de usuários da informação: comparação entre estudos de uso, de comportamento e de práticas a partir de uma pesquisa empírica. Informação em Pauta, Fortaleza, v. 1, n. 1, jan./jun. 2016. Disponível 
Rafaela Carolina Silva, Selma Letícia Capinzaiki Ottonicar, Rosângela Formentini Caldas, Cláudio Marcondes de Castro Filho

A competência em informação e o comportamento informacional dos usuários de bibliotecas híbridas: um estudo comparativo no Brasil e na Escócia

em: <http://www.periodicos.ufc.br/informacaoempauta/article/view/2970>. Acesso em: 20 set. 2017.

ASSOCIATION OF COLLEGE \& RESEARCH LLIBRARIES. Framework for Information Literacy for Higher Education. 2015. Disponível em:

<http://www.ala.org/acrl/standards/ilframework>. Acesso em: 26 set. 2017.

BELLUZZO, R.C.B. Construção de mapas: desenvolvendo competências em informação e comunicação. Bauru: Autores Brasileiros, 2007.

DEWE, M. Planning public library buildings: concepts and issues for the librarian. Londres: Routledge, 2016.

DUARTE, E. J.; CALDIN, C., F. Estética: uma dimensão da Competência em informação a ser percebida por bibliotecário de biblioteca pública. Informação e Sociedade, João Pessoa, v. 26, n. 2, p. 7-23, maio/ago. 2016. Disponível em: $<$ http://www.ies.ufpb.br/ojs/index.php/ies/article/view/29265/16193>. Acesso em: 03 jun. 2017.

GARCEZ, E. M. S; RADOS, G. J. V. Biblioteca híbrida: um novo enfoque no suporte à educação a distância. Ciência da Informação, Brasília, v. 31, n. 2, p. 44-51, maio/ago. 2002. Disponível em: <http://www.scielo.br/pdf/ci/v31n2/12907.pdf>. Acesso em: 17 maio 2014.

GASQUE, K. C. D. G; COSTA, S. M. S. Evolução teórico-metodológica dos estudos de comportamento informacional de usuários. Ciência da Informação, Brasília, v. 39 n. 1, p. 21-32, jan./abr. 2010. Disponível em:

<http://www.scielo.br/pdf/ci/v39n1/v39n1a02.pdf>. Acesso em: 26 set. 2017.

GOMES, M. A.; DUMOND, L. M. M. A noção de competência em informação e a de sociologia da educação e do trabalho: embate epistemológico. InCID, Ribeirão Preto, v. 6, n. 2, p. 84-105, set. 2015/fev. 2016. Disponível em: $<$ https://www.revistas.usp.br/incid/article/view/89929>. Acesso em: 15 ago. 2017.

LAU, J. Diretrizes sobre desenvolvimento de habilidades de informação para a aprendizagem permanente. The Haague: IFLA, 2007. Disponível em: $<$ http://www.ifla.org/files/assets/information-literacy/publications/iflaguidelinespt.pdf>. Acesso em: 08 set. 2017.

LIMA, T. C. S. de; MIOTO, R. C. T. Procedimentos metodológicos na construção do conhecimento científico: a pesquisa bibliográfica. Revista Katál, Florianópolis, v. 10, n. esp., p. 37-45, 2007. Disponível em: $<$ http://www.scielo.br/pdf/rk/v10nspe/a0410spe.pdf>. Acesso em: 25 set. 2017. 
Rafaela Carolina Silva, Selma Letícia Capinzaiki Ottonicar, Rosângela Formentini Caldas, Cláudio Marcondes de Castro Filho

A competência em informação e o comportamento informacional dos usuários de bibliotecas híbridas: um estudo comparativo no Brasil e na Escócia

LIMBERG, L.; SUNDIN, O.; TALJA, A. Three Theoretical perspectives on information literacy. HUMAN IT, v. 11, n. 2, p. 93-130, 2012. Disponível em: $<$ https://humanit.hb.se/article/view/69/51>. Acesso em: 05 ago. 2017.

LLOYD, A. Information literacy and literacies of information: a mid-range theory and model. Journal of Information Literacy, v. 11, n. 1, p. 91-105, 2017. Disponível em: <https://ojs.Iboro.ac.uk/JIL/article/view/PRA-V11-I1-5>. Acesso em: 25 set. 2017.

LWOGA, E. T. Mapping information literacy outcomes and learning experiences of health sciences undergraduate students. Partnership: the Canadian Journal of Library and Information Practice and Research, v. 9, n. 1, 2014. Disponível em:

$<$ https://journal.lib.uoguelph.ca/index.php/peri/article/view/2695/3219\#.Wcrw7si GPIU>. Acesso em: 22 jul. 2017.

MALAQUIAS, F. F. de O. et al. Comportamento informacional: um estudo com alunos do curso de administração. Revista Estudo \& Debate, Lajeado, v. 24, n. 2, 2017. Disponível em: <http://univates.br/revistas/index.php/estudoedebate/article/view/1292/1190>. Acesso em: 20 set. 2017.

MATINEZ-SILVEIRA, M.; ODDONE, N. Necessidades e comportamento informacional: conceituação e modelos. Ciência da Informação, Brasília, v. 36, n. 1, p. 118-127, maio/ago. 2007. Disponível em: <http://www.scielo.br/pdf/ci/v36n2/12.pdf>. Acesso em: 20 set. 2017.

OPPENHEIM, C.; SMITHSON, D. What is the hybrid library? Journal of Information Science, Reino Unido, v. 25, n. 2, p. 97-112, out./nov. 1999. Disponível em: <http://jis.sagepub.com/content/25/2/97.full.pdf+html>. Acesso em: 17 jan. 2015.

PIRES, E. A. N. Comportamento informacional e processo de busca da informação: bases fundamentais para pesquisa científica. Revista ACB, Florianópolis, v.17, n.2, p. 288-307, jul./dez. 2012.

POZO, J. I. A Sociedade da Aprendizagem e o desafio de converter informação em conhecimento. Revista Pátio, ano 8, ago./out. 2004. Disponível em: <http://www.udemo.org.br/A\%20sociedade.pdf>. Acesso em: 17 ago. 2015.

RGU.AC.UK. Library. 2016. Disponível em: <http://www.rgu.ac.uk/staff-andcurrent-students/library/library/>. Acesso em: 15 jun. 2016.

RUSSELL, R.; GARDNER, T.; MILLER, P. Hybrid information environments: overview and requirements. 1999. Disponível em: <http://www.ukoln.ac.uk/dlis/models/requirements/overview/>. Acesso em: 20 jan. 2015. 
Rafaela Carolina Silva, Selma Letícia Capinzaiki Ottonicar, Rosângela Formentini Caldas, Cláudio Marcondes de Castro Filho

A competência em informação e o comportamento informacional dos usuários de bibliotecas híbridas: um estudo comparativo no Brasil e na Escócia

SILVA, A. M. da. Ciência da Informação e comportamento informacional: enquadramento epistemológico do estudo das necessidades de busca, seleção e uso. Revista de Ciências e Tecnologias de Informação e Comunicação, Porto, n. 21, 2013. Disponível em:

$<$ http://revistas.ua.pt/index.php/prismacom/article/view/2659>. Acesso em: 20 set. 2017.

SILVA, R. C. da. Gestão de bibliotecas públicas no contexto híbrido: um estudo comparativo de bibliotecas híbridas no âmbito nacional e internacional em prol do desenvolvimento de comunidades. 2017. 288 f. Dissertação (Mestrado em Ciência da Informação) - Universidade Estadual Paulista, Faculdade de Filosofia e Ciências, Marília. Disponível em:

<https://repositorio.unesp.br/handle/11449/150798>. Acesso em: 31 jul. 2017.

SILVIA, P. M. O comportamento dos usuários de bibliotecas em sistemas de informação. TransInformação, Campinas, v. 20, n. 3, p. 255-263, set./dez. 2008. Disponível em: <http://www.scielo.br/pdf/tinf/v20n3/04.pdf>. Acesso em: 10 ago. 2017.

UNESCO. Towards Information literacy indicators. Paris: UNESCO, 2008. Disponível em: <http://unesdoc.unesco.org/images/0015/001587/158723e.pdf>. Acesso em: 12 set. 2017.

WILSON, T. D.; WALSH, C. Information behavior: an interdisciplinary perspective. Sheffield: University of Sheffield, 1996. Disponível em:

<http://informationr.net/tdw/publ/infbehav/cont.html>. Acesso em: 13 ago. 2015.

WILSON, T. D. On user studies and information needs. Journal of Documentation, v. 31, n. 1, p. 3-15, 1981. Disponível em:<http://www.emeraldinsight.com/doi/abs/10.1108/eb026702>. Acesso em: 03 set. 2017.

YIN, R. Estudo de caso: planejamento e métodos. Porto Alegre: Bookman, 2005.

\title{
THE INFORMATION LITERACY AND THE INFORMATION BEHAVIOUR OF HYBRID LIBRARIES USERS: A COMPARATIVE STUDY BETWEEN BRAZIL AND SCOTLAND
}

\begin{abstract}
Introduction: Hybrid libraries offer many resources to users. They need to be information literate to be able to access, evaluate and use information in those libraries. Furthermore, they need to develop their informational behavior to access information effectively. Objectives: This paper aims to discuss the relationship between
\end{abstract}


Rafaela Carolina Silva, Selma Letícia Capinzaiki Ottonicar, Rosângela Formentini Caldas, Cláudio Marcondes de Castro Filho

A competência em informação e o comportamento informacional dos usuários de bibliotecas híbridas: um estudo comparativo no Brasil e na Escócia

information literacy, information seeking behavior and hybrid libraries. Methodology: The content analysis was used to develop hybrid library standards. The multiple case study was used to compare the relationship between information literacy and information seeking behavior in the context of hybrid libraries in Brazil and the United Kingdom. Results: The literature review and the multiple case study contributed to the creation of a chart which connected those themes. Conclusion: Hybrid libraries use information literacy and information seeking behavior to help users. The goals of the libraries meet the users' needs.

Descriptors: Information literacy. Information behaviour. Hybrid libraries. Libraries.

\title{
LA ALFABETIZACIÓN Y EL COMPORTAMIENTO INFORMACIONAL DE LOS USUARIOS EN BIBLIOTECAS HÍBRIDAS: ESTUDIO COMPARATIVO ENTRE BRASIL Y ESCOCIA
}

\begin{abstract}
RESUMEN
Introducción: Las bibliotecas híbridas ofrecen muchos recursos a los usuarios. Deben ser expertos en información para poder acceder, evaluar y usar la información en esas bibliotecas. Además, necesitan desarrollar su comportamiento informativo para acceder a la información de manera efectiva. Objetivos: Este trabajo tiene como objetivo estudiar la relación existente entre los conceptos de alfabetización informacional y comportamiento informacional en el contexto de las bibliotecas híbridas. Metodología: Con el análisis de contenido se pudieron determinar los indicadores de bibliotecas híbridas que serán estudiados. Además, se utilizó el estudio de casos múltiples para comparar la relación entre competencias y comportamiento informacional de los usuarios en las bibliotecas híbridas de Brasil y Reino Unido. Resultados: El desarrollo de la investigación facilitó la elaboración de un cuadro teórico donde se inter-relacionan las temáticas estudiadas en el ámbito de la hibridez. Consideraciones: Como consideraciones finales se destaca que las bibliotecas híbridas se basan en los conceptos de competencia y comportamiento informacional para conocer las necesidades reales de información de sus usuarios.
\end{abstract}

Descriptores: Alfabetización informativa. Comportamiento informacional. Bibliotecas híbridas. Bibliotecas. 